\title{
Preparation of Oxidized Enset (Ensete ventricosum) Starch and its Characterization
}

\author{
Asaminew Zeleke, Abrham Temesgen*, Tesfa Marew, Tesfaye Gabriel, \\ Muluken Nigatu and Yonas Brhane
}

Department of Pharmaceutics and Social Pharmacy, Addis Ababa University, Ethiopia; asex2008@gmail.com, abrham.temesgen@aau.edu.et, tesfa.marew@aau.edu.et, tesfaye.gabriel@aau.edu.et, muluken.nigatu@aau.edu.et, yonas.brhane@aau.edu.et

\begin{abstract}
Objective: Native starches possess poor characters which need to be improved by modification to increase the spectrum of their industrial applicability. The present study aims to synthesize and characterize oxidized enset [Ensete ventricosum] starch. Methods: Native enset starch was isolated and modified through oxidation using $30 \% \mathrm{w} / \mathrm{w}$ hydrogen peroxide $\left(\mathrm{H}_{2} \mathrm{O}_{2}\right)$ solution in alkaline $\mathrm{pH}$ for 30, 60, 90 and 120 minutes. The carbonyl and carboxyl contents as well as XRD and FT-IR patterns were determined for the oxidized starches. Solubility and swelling characteristics, density and related properties were also investigated in comparison to the native starch. Findings: $\mathrm{H}_{2} \mathrm{O}_{2}$ oxidation of enset starch resulted higher value for carbonyl contents ( 0.46 to 0.56 ) than carboxyl contents ( 0.17 to 0.18 ) and it increased the solubility while decreasing swelling power of enset starch. Oxidized starches showed increase in solubility in the order Oxi 120>0xi 90>0xi 60>0xi 30. Oxidation at different reaction times did not bring change in XRD patterns instead alteration of intensity of major diffraction peaks was observed. This implies the present condition of oxidation didn't bring change in crystal type but the intensity change may indicate that degree of crystallinity was reduced. The oxidized enset starch showed poor flow and compressibility as it is evident in the calculated values of Hausner ratio, Carr's index and angle of repose. Application/ Improvement: Ensete ventricosum, widely cultivated in southern and south western Ethiopia and rich in starch, can be oxidized using a simple and eco-friendly technique for its potential applicability in the food and pharmaceutical industries.
\end{abstract}

Keywords: Carbonyl Content, Carboxyl Content, Enset Starch, Hydrogen Peroxide, Oxidized Starch

\section{Introduction}

Starch is widely available carbohydrate polymer found in different plant organs. A range of native starches with different functionalities sourced from different plant species are currently available in the market. Each of these starches is different from the other as they have distinct chemical composition and physical property ${ }^{1}$. Starch is a polymer of two building blocks called amylose and amylopectin. Amylose is the linear polymer consisting of D-glucopyranose units linked by $\alpha-1,4$-acetal linkages. Amylopectin is a much larger and branched chain containing $\alpha-1,4$ linear bonds and with branching through $\alpha-1,6$ linkages 2 .

${ }^{*}$ Author for correspondence
Ethiopian plants which have been reported to be rich source of starch include enset ${ }^{3}$, Dioscorea ${ }^{4}$, Godare ${ }^{5}$ and Cassava ${ }^{6}$. Enset (Ensete ventricosum (Welw.) Cheeseman) plant belongs to the family Musaceae and the genus ensete. It is so-called false banana as it looks like a banana plant without edible fruits ${ }^{3}$.

While it is distributed in eastern and Southern Africa, E. ventricosum is a widely cultivated staple crop in southern and south western parts of Ethiopia. It accumulates starch mainly in the pseudo-stem and underground corms ${ }^{7}$.

Changing the physico-chemical properties of native starch to improve its inherent poor characteristics such as 
low shear resistance, thermal degradation and tendency of retrogradation has been used to modify starch for specific applications ${ }^{8}$. Starch modification aims at introducing required functional groups in starch structure so as to produce derivatives of predictable and controllable properties. Techniques of modification reported so far include chemical, physical, enzymatic and genetic modifications ${ }^{9}$. Oxidation using different oxidizing agents is one of the chemical methods employed. The present study aimed to oxidize enset starch using $\mathrm{H}_{2} \mathrm{O}_{2}$ and to characterize it.

\section{Materials and Methods}

\subsection{Materials}

The chemicals and reagents used in this study include hydroxylamine (BDH Chemicals Ltd, England), copper sulfate (Banbury Oxon, UK) and hydrogen peroxide (30\%) (Fine chemicals, Addis Ababa, Ethiopia) and other analytical grade reagents were used as received.

\subsection{Enset Starch Isolation}

Native starch was isolated from enset boulla employing are ported method. The purified starch slurry was filtered and dried in open air at room temperature and packed in plastic bags until the modification process ${ }^{3}$.

\subsection{Oxidation of Enset Starch}

Oxidation of enset starch was conducted using the method reported elsewhere with minor modification ${ }^{10}$. Forty percent starch slurry was prepared in distilled water. The reaction mixture adjusted to $\mathrm{pH} 10$ using $2 \mathrm{~N} \mathrm{NaOH}$. Copper sulfate was used to catalyze the reaction $(0.1 \%$ based on starch). The temperature was maintained at $40^{\circ} \mathrm{C}$ and $\mathrm{H}_{2} \mathrm{O}_{2}$ solution (30\%) was added drop wise manner over a 15 minutes period while stirring the mixture over a magnetic stirrer. Final concentration of $\mathrm{H}_{2} \mathrm{O}_{2}$ attained will be $3 \%$ with respect to the starch. $\mathrm{pH}$ was continuously monitored and maintained at the desired value with $\mathrm{NaOH}$ solution. Reaction was conducted for the duration 30, 60, 90 and 120 minutes counted after incorporation of all reagents. At the end of each reaction, contents of the reaction flasks were filtered and diluted with distilled water while adjusting the $\mathrm{pH}$ to 7 . The suspensions were again filtered, washed four times with distilled water, filtered after each washing and oven-dried (Kottermann 2711, Germany) at $50^{\circ} \mathrm{C}$. Products were powdered and kept in tight glass containers for further characterization.

\subsection{Carbonyl Content Determination}

Carbonyl content of oxidized enset starch was determined by a previously reported titrimetric method using hydroxylamine reagent $t^{11}$. Using the titer values (of $0.1 \mathrm{~N}$ $\mathrm{HCl}$ ) obtained for the sample and blank determinations, carbonyl content was calculated using Equation 2.1.

$$
\begin{aligned}
& \text { Carbonyl content }(\%)= \\
& \frac{[(\operatorname{blank}(\mathrm{ml})-\text { sample }(\mathrm{ml})) \times 0.1 \times 0.028]}{\text { Sample weight }(\mathrm{g})} \times 100
\end{aligned}
$$

\subsection{Carboxyl Content Determination}

Carboxyl content was determined following the method described elsewhere ${ }^{11}$. Tests were done for the oxidized enset starch (samples) and the native one (blank), then using volumes of $0.01 \mathrm{~N} \mathrm{NaOH}$ consumed carboxyl content was calculated according to Equation 2.2.

Carboxyl content $(\%)=$

$$
\frac{[(\operatorname{sample}(\mathrm{ml})-\text { blank }(\mathrm{ml})) \times 0.01 \times 0.045]}{\text { Sample weight }(\mathrm{g})} \times 100
$$

\subsection{Solubility and Swelling Power}

A reported method with minor modification was used to study solubility and swellability $\underline{12}$. Starch samples $(0.4$ g) were added into dried $15 \mathrm{ml}$ graduated centrifuge tubes. Twelve milliliters of distilled water was added to each and contents of the tubes were mixed after capping. Tubes were then placed in a water bath (Gesellschaft fur Labortecnnic mbH, Germany) maintained at 55, 65, 75 and $95^{\circ} \mathrm{C}$ with repeated shaking for $30 \mathrm{~min}$. Then, cooled samples were centrifuged at $3000 \mathrm{rpm}$ for 15 min and supernatant obtained was dried and weighed. The result obtained represent amount of solubilized starch. Equations 2.3 and 2.4 were employed to calculate solubility and swelling power.

$$
\begin{aligned}
& \text { Solubility }(\%)=\frac{\text { weight of soluble starch }}{\text { weight of sample }} \times 100 \\
& \text { Swelling power }(\%)= \\
& \frac{\text { weight of sediment paste }(\mathrm{g})}{[\text { weight of sample } \times(100-\% \text { solubility })]} \times 100
\end{aligned}
$$




\subsection{Determination of Density and Flow Properties}

Density was determined using tapped densitometer (ERWEKA, Germany) by placing thirty grams of native and oxidized starches into $250 \mathrm{ml}$ measuring cylinder. Bulk density (as $\mathrm{g} / \mathrm{ml}$ ) was calculated from the weight of the powder and the volume it occupied. Cylinder containing the powder was then tapped for $1 \mathrm{~min}$ by dropping it from a fixed one-half inch at rate of 250 taps/ $\mathrm{min}$. The new volume reading was used to calculate the tapped density which in turn is used to calculate Carr's index and Hausner ratio (Equations 2.5 and 2.6) $\frac{13}{}$.

Carr's index $=\frac{\text { tapped density }- \text { bulk density }}{\text { [tapped density }]} 1002.5$

Hausner ratio $=\frac{\text { tapped density }}{\text { bulk density }}$

Thirty grams of starch powder was allowed to flow through a stemless funnel having a $15 \mathrm{~mm}$ opening from a $10 \mathrm{~cm}$ height to determine rate of flow and angle of repose. Time taken, in second, by the powder to flow and average diameter and height of the powder piles formed were recorded. Flow rate was determined as mass in gram per time in second. Angle of repose was determined using Equation 2.7.

$$
\text { Angle of repose }(\theta)=\tan ^{-1}\left(\frac{h}{r}\right)
$$

Where $\mathrm{h}$ and $\mathrm{r}$ are the height and radius of the starch powder pile, respectively.

\subsection{Powder X-ray Diffraction Study}

The X-ray powder diffraction study was done for native and oxidized enset starches using an X-ray diffractometer (Bruker AXS, Bavart Zulassung, BW/508/98/Ro, Germany) operating in the $2 \theta$ modes. $\mathrm{A} \mathrm{Cu}$ target tube operated at a power setting of $40 \mathrm{kV}(15 \mathrm{~mA})$, receiving slit $13.0 \mathrm{~mm}$, in the range of $2-90^{\circ}$ of $2 \theta$ with single crystal graphite monochromator equipped with a microprocessor to analyze peak position and intensities was utilized. Standard polycrystalline silicon powder was used to calibrate the equipment. Crystal type of oxidized enset starch was determined based on the major diffraction peaks in comparison to that of the unmodified enset starch.

\subsection{Fourier Transforms Infrared (FT-IR) Spectroscopy}

FT-IR spectra of starch samples were scanned at room temperature using FT-IR spectrophotometer (Model SHIMADZU FT-IR-8400S, Japan) in transmittance mode. Wave numbers covered during scanning were between 4000 and $400 \mathrm{~cm}^{-1}$ at a $4 \mathrm{~cm}^{-1}$ resolution. Scans were taken using background spectrum corresponding to pure potassium bromide $(\mathrm{KBr})$ plate. Discs were prepared by compressing starch samples with $\mathrm{KBr}$ (Minipress, Jasco, Japan) and they were scanned to observe characteristic peaks.

\section{Results and Discussion}

\subsection{Carbonyl and Carboxyl Contents}

Carbonyl and carboxyl contents at different reaction times of oxidized enset starch are shown in Table 1. Higher carbonyl contents than carboxyl contents were recorded in the oxidized starches. During oxidation process, starch hydroxyl groups first convert into carbonyl and then to carboxyl groups ${ }^{11}$. This arises because the oxidant, $\mathrm{H}_{2} \mathrm{O}_{2}$, could have reacted with starch so rapidly that most of it was consumed during the early period of reaction yielding high amount of carbonyl groups. Thus, less oxidant was available or further oxidation of carbonyl to carboxyl groups.

Table 1 also depicts that carbonyl and carboxyl contents varied very little between 30 and 120 minutes reaction times indicating that enset starch oxidation by $\mathrm{H}_{2} \mathrm{O}_{2}$ was almost completed soon after its start within the first 30 minutes. Similar findings were reported for oxidation of cassava starch with $\mathrm{H}_{2} \mathrm{O}_{2} \frac{14}{}$.

Elsewhere, scientists investigated effect of reaction time on degree of oxidation of corn starch is by using $\mathrm{H}_{2} \mathrm{O}_{2} \frac{15}{2}$. According to their findings, degree of oxidation changed significantly up to $60 \mathrm{~min}$ reaction time while it showed marginal change afterwards.

Similarly, potato starch was modified in alkaline conditions using $\mathrm{H}_{2} \mathrm{O}_{2}$ as oxidizing agent and $\mathrm{CuSO}_{4}$ as catalyst. They could observe only increase in the carbonyl contents whereas no significant change in carboxyl contents between 1 and 4 hrs of reaction time ${ }^{10}$. 
Reports showed that peroxide oxidation is different from starch oxidation by hypochlorite in terms of change in carbonyl and carboxyl content. Hypochlorite oxidation resulted in increased carboxyl contents with increasing reaction time while the carbonyl contents tended to remain constant or decline $e^{10,16}$.

Reaction of $\mathrm{H}_{2} \mathrm{O}_{2}$ with starch has been reported to involve a complex radical chain reaction. $\mathrm{H}_{2} \mathrm{O}_{2}$, in the presence of metal catalysts, rapidly decomposes into highly reactive hydroxyl radicals $(\mathrm{HO} \bullet)$ which are reactive enough to withdraw hydrogen from $\mathrm{C}-\mathrm{H}$ group of the glucose ring. This in turn forms another radical which further undergoes acid/base catalyzed rearrangement and results cleavage of glycosidic bond and formation of carbonyl groups ${ }^{17}$. Free carbonyl groups of carbohydrates could undergo further reactions in alkaline environments yielding a carboxyl group ${ }^{18}$. Being highly reactive, hydroxyl radical has been reported to react with carbohydrates exceedingly rapidly and this could probably explain the pattern of functional group formation observed in the study ${ }^{19}$.

Table 1. Carbonyl and carboxyl contents of $\mathrm{H}_{2} \mathrm{O}_{2}$ oxidized enset starch at different reaction times

\begin{tabular}{|c|c|c|}
\hline $\begin{array}{c}\text { Modified } \\
\text { starch }(*)\end{array}$ & $\begin{array}{c}\text { Carbonyl } \\
\text { content } \\
\text { (\% CO) }\end{array}$ & $\begin{array}{c}\text { Carboxyl content } \\
\text { (\% COOH) }\end{array}$ \\
\hline Oxi 30 & 0.46 & 0.18 \\
\hline Oxi 60 & 0.49 & 0.17 \\
\hline Oxi 90 & 0.53 & 0.17 \\
\hline Oxi 120 & 0.56 & 0.18 \\
\hline
\end{tabular}

$\left(^{*}\right)$ Oxi30: enset starch oxidized for $30 \mathrm{~min}$, Oxi60: enset starch oxidized for $60 \mathrm{~min}$, Oxi90: enset starch oxidized for 90 min, Oxi120: enset starch oxidized for $120 \mathrm{~min}$

\subsection{Solubility and Swelling Power}

In hot aqueous dispersions, starch granules hydrate and swell with a consequent leaching of some soluble components. The degree of swelling and leaching of soluble components are affected by the strength of bonds within the granules. Other major factors that affect swelling power and solubility of starches include amylose/amylopectin ratio, molecular weight distribution and polymer chain length, degree of branching and conformation ${ }^{20}$ and proportion of non-carbohydrate (i.e. lipid and protein) components $s^{21}$.
Rise in temperature resulted in increase in swelling power and solubility for all the studied starches (Figures $1 \mathrm{a}$ and $1 \mathrm{~b}$ ). These results are agreement with the previous observations ${ }^{3,22,23}$.

Native enset starch showed lower solubility compared to the oxidized starches at all temperatures (Figure 1a). Generally, solubility of starch has been reported to increase upon oxidation due to the associated degradation effect of oxidation on the starch granules.

The low solubility of Oxi30 from among the oxidized starches might be caused by the cross-linking that occurs in slightly oxidized starch. In a previous study, it was explained that initially formed aldehyde groups at low amount of oxidant could form hemiacetal cross linking among oxidized starches. These cross-linking phenomena would stabilize the swelling and also reduce solubility by preventing leaching out of amylopectin ${ }^{24}$.

However, at a high level of oxidation, the Oxi120 had much increased water solubility compared to the Oxi30 apparently due to depolymerization of the amylose and amylopectin fractions and breakup of the starch granules as a whole ${ }^{25,26}$.

At all the studied temperatures, oxidation resulted lower swelling power compared to the native enset starch. The higher swelling power seen native enset starch could be probably due to longer chains in amylopectin structure and the more intact granular structure ${ }^{27}$.

As regards to solubility, oxidized starches showed better solubility at all temperatures. Oxidation increased solubility of enset starch in the order Oxi 120>Oxi 90>Oxi $60>$ Oxi 30 probably because of the weakening of starch granules during the process ${ }^{28}$.

Oxidation reduced swelling power of enset starch as duration of treatment with $\mathrm{H}_{2} \mathrm{O}_{2}$ increased from 30 min to $120 \mathrm{~min}$. This could presumably be due to the structural disintegration of starch granules that reduced their water retaining capability. It is reported that degree of oxidation significantly reduced swelling power of potato starch as active chlorine concentration (oxidant) was increased from 0.1 to $4.0 \mathrm{~g} / 100 \mathrm{~g}^{29}$. Similar findings were also reported which indicate that oxidation reduces swelling behaviour of native $\operatorname{starch}^{30}$.

\subsection{Density and Flow Properties}

Bulk and tapped densities give an insight on the packing arrangement of particles and compaction profile of a powder ${ }^{31}$. Particle size and shape are among the factors 
a
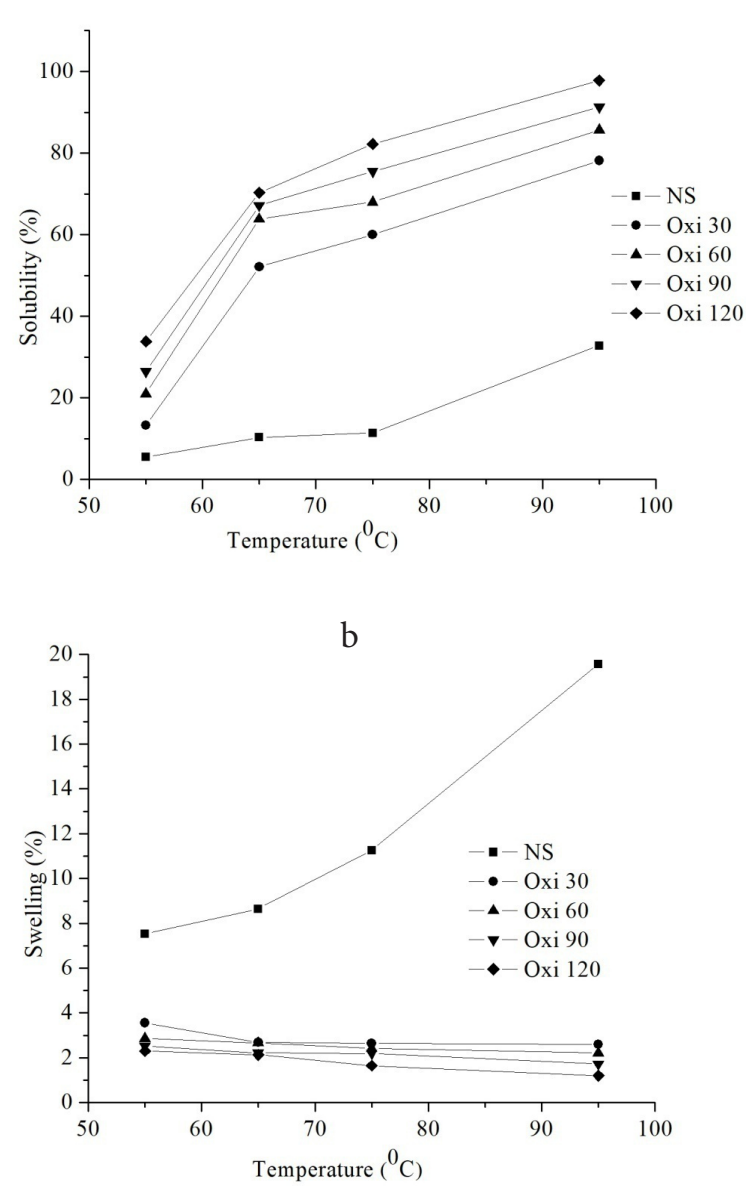

Figure 1. Solubility (a) and Swellability (b) of native and oxidized enset starches.

that affect density and hence, packing property of powder particles. Measures of flow and compressibility such as Carr's index and Hausner ratio are calculated from bulk and tapped densities ${ }^{32}$. Table 2 shows the flow and density derived properties of native and oxidized enset starch.

Native enset starch showed lower bulk and tapped densities compared to all the oxidized starches.
Accordingly, the unmodified and all oxidized enset starches showed poor compressibility and flow properties as their Carr's index and Hausner ratio are out of acceptable range ${ }^{33}$. The angle of repose and powder flow rate as well show the poor flow character of the studied starch samples.

\subsection{Powder X-ray Diffraction Study}

The crystal type of native starch granules is divided into A, B and C types. Type A crystallinity is observed in cereal starches while type B is common in tuber starches. The third and less common type is Type $\mathrm{C}$ which is a mixture of types A and B. Superimposed X-ray diffractogram of the native and oxidized enset starches is shown in Figure 2.

The diffractograms showed that the native enset starch exhibited sharp peaks appearing at around $2 \theta$ of $5,17,20,22,24^{\circ}$ which are typical of B-type crystals usually seen in tuber starches 3 . Oxidation of enset starch at different reaction times did not bring change in XRD peak positions. This indicates that the oxidation process didn't bring crystal type change. However, peaks for the oxidized starches diminished compared to the intense peaks of the native. This is in agreement with the finding of others where they explained that oxidation mainly took place in amorphous regions of starch affecting degree of crystallinity ${ }^{34}$. They observed that X-ray diffraction patterns of barley and corn starch granules were not altered upon oxidation with sodium hypochlorite at different levels. Kuakpetoon and Wang also found that potato starch oxidation at varying active chlorine concentrations mainly involved the amorphous region of starch granules, altering the degree of crystallinity ${ }^{29,35}$.

Our result, however, is different from a previous finding where crystal structure of corn starch was changed upon oxidation by $\mathrm{H}_{2} \mathrm{O}_{2}$ as they employed a prior

Table 2. Densities and related properties of native and oxidized enset starch (Mean $\pm S D, n=3$ )

\begin{tabular}{|l|c|c|c|c|c|}
\hline Powder Properties & Native & Oxi 30 & Oxi 60 & Oxi 90 & Oxi 120 \\
\hline Bulk density $(\mathrm{g} / \mathrm{ml})$ & $0.697 \pm 0.06$ & $0.769 \pm 0.13$ & $0.789 \pm 0.17$ & $0.732 \pm 0.1$ & $0.750 \pm 0.12$ \\
\hline Tapped density $(\mathrm{g} / \mathrm{ml})$ & $0.750 \pm 0.12$ & $0.812 \pm 0.19$ & $0.750 \pm 0.12$ & $0.769 \pm 0.13$ & $0.779 \pm 0.14$ \\
\hline Hausner ratio & $1.45 \pm 0.13$ & $1.56 \pm 0.19$ & $1.52 \pm 0.15$ & $1.51 \pm 0.14$ & $1.35 \pm 0.11$ \\
\hline Carr's index $(\%)$ & $26.1 \pm 1.03$ & $30 \pm 1.15$ & $32.0 \pm 1.17$ & $31 \pm 1.16$ & $33 \pm 1.18$ \\
\hline Flow rate & No flow & No flow & No flow & No flow & No flow \\
\hline Angle of repose & No flow & No flow & No flow & No flow & No flow \\
\hline
\end{tabular}


gelatinization step which could lead to destruction of starch granules freeing the hydroxyl groups for the increased oxidation and change in crystal structure ${ }^{\frac{15}{5}}$. In our study, the XRD patterns of oxidized enset starches showed no obvious change from that of the native. This could be an indication of the lower degree of oxidation achieved by the present procedure in which oxidation could apparently take place in the amorphous region while the crystalline portions didn't get well penetrated by the oxidant.

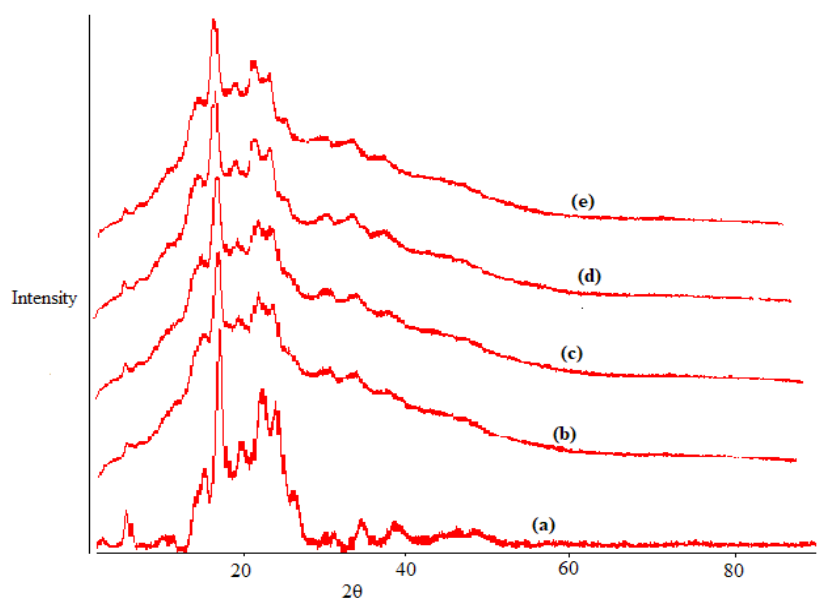

Figure 2. X-ray diffraction patterns of native enset starch (a); Oxi 30 (b); Oxi 60 (c); Oxi 90 (d) and Oxi 120 (e).

\subsection{Fourier Transforms Infrared (FT-IR) Spectroscopy}

The bands shown at around $1618 \mathrm{~cm}^{-1}$ in the FT-IR in spectra (Figure 3) could be assigned to deformational vibrations of water molecules bound to starch granules due to the hydrophilic property of $\operatorname{starch}^{36}$. Absorption peak at around $1458 \mathrm{~cm}^{-1}$ might be due to $\mathrm{C}-\mathrm{H}$ bending vibration.

As shown by the superimposed FTIR-spectrum, there is no observable difference between the spectra of native enset starch and the oxidized forms. This could apparently be due to the low levels of oxidation achieved by the method used. Studies utilizing other oxidizing agents also showed similarity of spectra between native and oxidized starches. Other investigators found similar results upon oxidation of barley starch using different levels of hypochlorite as oxidizing agent. Cassava starch oxidized with ozone at different $\mathrm{pH}$ conditions was also demonstrated to have similar spectra with the native $\operatorname{starch}^{37}$. This is in contrary to previous findings where a unique absorption peak assigned to $\mathrm{C}=\mathrm{O}$ stretching

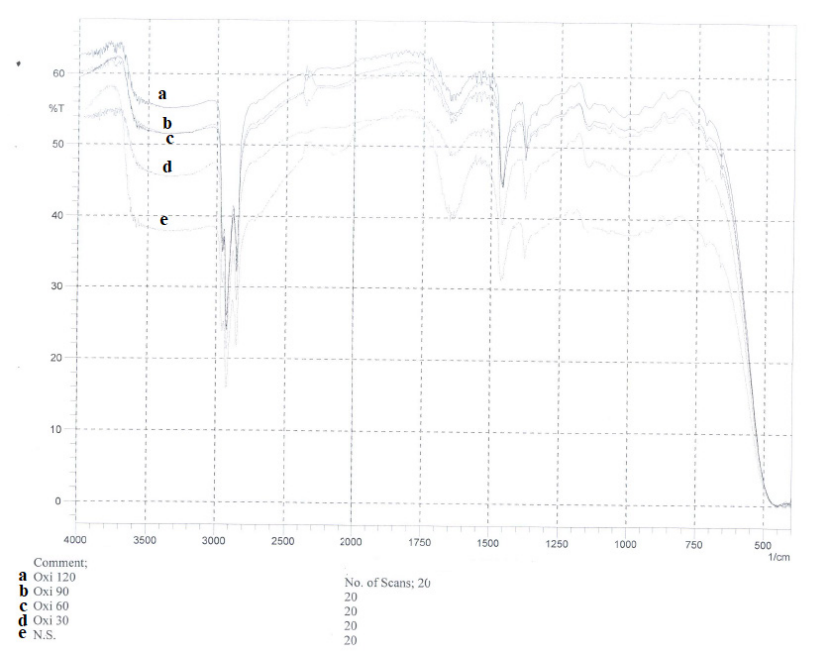

Figure 3. FTIR spectra of native and oxidized enset starches.

vibrations was observed at $1735 \mathrm{~cm}^{-1}$ in the $\mathrm{H}_{2} \mathrm{O}_{2}$ oxidized starches $\frac{15,36}{}$.

\section{Conclusion}

Enset starch was oxidized using $\mathrm{H}_{2} \mathrm{O}_{2}(30 \%)$ varying the reaction time for $30 \mathrm{~min}, 60 \mathrm{~min}, 90 \mathrm{~min}$ and $120 \mathrm{~min}$. The oxidation process yielded higher values of carbonyl contents than carboxyl contents. The procedure didn't bring crystal type of the starch. The typical B-type crystal structure and the major diffraction peaks of enset starch were retained despite an associated change in intensity of peaks were observed. It is evident that $\mathrm{H}_{2} \mathrm{O}_{2}$ oxidation increased solubility of native enset starch while it led to reduction of swelling apparently because of structural weakening and breakup of the starch granules. Both the native and oxidized enset starches showed poor flow property. Thus, oxidized enset starch can further be characterized in terms of other parameters for their potential applicability in the food and pharmaceutical industries.

\section{Acknowledgements}

The authors are grateful to Department of Pharmaceutics and Social Pharmacy, Addis Ababa University for providing access to the laboratory facilities. 


\section{References}

1. Copeland L, Blazek J, Salman H, Tang MC. Form and functionality of starch. Food Hydrocolloids. 2009; 23(6): 1527-34. https://doi.org/10.1016/j.foodhyd.2008.09.016

2. Nelson KG, Wang LY. Determination of time course of tablet disintegration I: Numerical method. Journal of Pharmaceutical Sciences.1977; 66(12):1758-61. PMid: 925944. https://doi.org/10.1002/jps.2600661227

3. Gebre-Mariam T, Schmidt PC. Isolation and physicochemical properties of enset starch. Starch/Starke.1996; 48(6):208-14. https://doi.org/10.1002/star.19960480603

4. Gebre-Mariam T, Schmidt PC. Some physicochemical properties of dioscorea starch from Ethiopia. Starch-Starke. 1998; 50(6):241-6. https://doi.org/10.1002/(SICI)1521379X(199806)50:6<241::AID-STAR241>3.0.CO;2-R

5. Adane M, Endale A, Bultosa G, Gemal M, Gebre-Mariam T. Isolation and physicochemical characterization of godare (Colocasiaesculenta) starch from Ethiopia. Ethiopian Pharmaceutical Journal. 2006; 24(1):13-22. https://doi. org/10.4314/epj.v24i1.35094

6. Paulos G, Endale A, Bultosa G, Gebre-MariamT. Isolation and physicochemical characterization of cassava starches obtained from different regions of Ethiopia. Ethiopian Pharmaceutical Journal. 2009; 27(1):1-12. https://doi. org/10.4314/epj.v27i1.51118

7. Debebe A, Chandravanshi SB and Wondimu T, Yesuf $M$ and Hunduma T. Studies of Enset Ventricosum for major, minor and trace elements.2006.http://etd.aau.edu.et/handle/123456789/820

8. Singh J, Kaur L, McCarthy OJ. Factors influencing the physicochemical, morphological, thermal and rheological properties of some chemically modified starches for food application - A review. Food Hydrocolloids. 2007; 21(1):122. https://doi.org/10.1016/j.foodhyd.2006.02.006

9. Tharanathan RN. Starch value addition by modification. Critical Reviews in Food Science and Nutrition. 2005; 45(5):371-84. PMid: 16130414. https://doi. org/10.1080/10408390590967702

10. Parovuori P, Hamunen A, ForssellP, Autio K, Poutanen K. Oxidation of potato starch by hydrogen peroxide. Starch-Starke. 1995; 47(1):19-23. https://doi.org/10.1002/ star. 19950470106

11. Wang YJ, Wang L. Physicochemical properties of common and waxy Corn starches oxidized by different levels of sodium hypochlorite. Carbohydrate Polymers. 2003; 52(3):207-17. https://doi.org/10.1016/S0144-8617(02)003041

12. AhamedNT,SinghalRS,KulkamiPR,PalM.Physicochemical and functional properties of Chenopodium quinoa starch. Carbohydrate Polymers.1996; 31(1-2):99-103. https://doi. org/10.1016/S0144-8617(96)00034-3
13. Schussele A, Bauer-Brandl A. Note on the measurement of flowability according to the European Pharmacopoeia. International Journal of Pharmaceutics. 2003; 257(1-2): 301-4. https://doi.org/10.1016/S0378-5173(03)00142-X

14. Sangseethong K, Termvejsayanon N, Sriroth K. Characterization of physicochemical properties of hypochlorite - and peroxide-oxidized cassava starches. Carbohydrate Polymers. 2010; 82(2):446-53. https://doi. org/10.1016/j.carbpol.2010.05.003

15. Zhang YR, Wang XL, Zhao GM, Wang YZ. Preparation and properties of oxidized starch with high degree of oxidation. Carbohydrate Polymers. 2012; 87(4):2554-62. https://doi. org/10.1016/j.carbpol.2011.11.036

16. Sangseethong K, Lertphanich S, Sriroth K. Physicochemical properties of oxidized cassava starch prepared under various alkalinity levels. Starch-Starke. 2009; 61(2):92-100. https://doi.org/10.1002/star.200800048

17. Arts SJHF, Mombarg EJM, van Bekkum H, Sheldon RA. Hydrogen peroxide and oxygen in catalytic oxidation of carbohydrates and related compounds. Synthesis. 1997; 1997(6):597-613. https://doi.org/10.1055/s-1997-1406

18. Isbell HS, Frush HL. Mechanisms for hydroperoxide degradation of disaccharides and related compounds. Carbohydrate Research. 1987; 161(2):181-93. https://doi. org/10.1016/S0008-6215(00)90076-4

19. Fry SC. Oxidative scission of plant cell wall polysaccharides by ascorbate induced hydroxyl radicals. Biochemical Journal. 1998; 332(2):507-51. PMid: 9601081 PMCid: PMC1219507. https://doi.org/10.1042/bj3320507

20. Chen Z. Physicochemical properties of sweet potato starches and their application in noodle products.2003. https://edepot.wur.nl/121460

21. Schoch TJ. Swelling power and solubility of granule starches. Whistler RL Editor. Methods in carbohydrate chemistry, Vol IV: Starch. London: Academic Press; 1994. p. 106-8.

22. Adebowale $\mathrm{KO}$, Afolabi TA, Lawal OS. Isolation, chemical modification and physicochemical characterization of Bambara groundnut (Voandezia subterranean) starch and flour. Food Chemistry.2002; 78(3):305-11. https://doi. org/10.1016/S0308-8146(02)00100-0

23. Lawal OS. Composition, physicochemical properties and retrogradation characteristics of native, oxidized and acetylated and acid-thinned new cocoyam starch. Food Chemistry. 2004; 87(2):205-18. https://doi.org/10.1016/j. foodchem.2003.11.013

24. El Halal SLM, Colussi R, Pinto VZ, Bartz J, Radunz M, Carreño NLV, Dias ARG, Zavareze ER. Structure, morphology and functionality of acetylated and oxidized barleystarches. Food Chemistry. 2015; 168(1):247-56. PMid: 25172707. https://doi.org/10.1016/j.foodchem.2014.07.046 
25. Wing RE. Oxidation of starch by thermo chemical processing. Starch-Starke.1994; 46(11):414-8. https://doi. org/10.1002/star.19940461103

26. Paterson LA, Hashim DB, Hill SE, Mitchell JR, Blanshard JM. The effect of low levels of sulphite on the swelling and solubility of starches. Starch-Starke. 1994; 46(8):288-91. https://doi.org/10.1002/star.19940460803

27. Sasaki T, Matsuki J. Effect of wheat structure on swelling power. Cereal Chemistry. 1998; 75(4):525-9. https://doi. org/10.1094/CCHEM.1998.75.4.525

28. Adebowale KO, Afolabi TA, Olu-Owolabi BI. Functional, physicochemical and retrogradation properties of sword bean (Canavaliagladiata) acetylated and oxidized starches. Carbohydrate Polymers. 2006; 65(1):93-101. https://doi. org/10.1016/j.carbpol.2005.12.032

29. Zhou F, Liu Q, Zhang H, Chen Q, Kong B. Potato starch oxidation induced by sodium hypochlorite and its effect on functional properties and digestibility. International Journal of Biological Macromolecules. 2016; 84:410-7. PMid: 26712699. https://doi.org/10.1016/j.ijbiomac.2015.12.050

30. Sukhija S, Singh S, Riar CS. Effect of oxidation, cross-linking and dual modification on physicochemical, crystallinity, morphological, pasting and thermal characteristics of elephant foot yam (Amorphophalluspaeoniifolius) starch. Food Hydrocolloids. 2016; 55:56-64. https://doi. org/10.1016/j.foodhyd.2015.11.003

31. Sarangapani S, Rajappan M. Pharmacognostical and pharmaceutical characterisation of delonixregia - a novel matrix forming natural poymer. International Journal of Pharmacy. 2012; 2:564-73.

32. Odeku O, Picker-Freyer K. Evaluation of the material and tablet formation properties of modified forms of Dioscorea starches. Drug Development and Industrial Pharmacy. 2009; 35(11):1389-406. PMid: 19832640. https://doi. org/10.3109/03639040902960185

33. Wells J. Pharmaceutical preformulation: the physicochemical properties of drug substances. Journal of Pharmaceutical Sciences. 1990; 79(6):553-3. https://doi. org/10.1002/jps.2600790622

34. Chavez-Murillo ECM, Wang YJ, Luis ABP. Morphological, physicochemical and structural characteristics of oxidized barley and corn starches. Starch-Starke. 2008;60(11):634-45. https://doi.org/10.1002/star.200800016

35. KuakpetoonD, WangYJ.Characterization ofdifferentstarches oxidized by hypochlorite. Starch-Starke. 2001; 53(5):211-8. https://doi.org/10.1002/1521-379X(200105)53:5<211:: AID-STAR211>3.0.CO;2-M

36. Zhang SD, Zhang YR, Wang XL, Wang YZ. High carbonyl content oxidized starch prepared by hydrogen peroxide and its thermoplastic application. Starch-Starke. 2009; 61(11):646-55. https://doi.org/10.1002/star.200900130

37. Klein B, Vanier NL, Moomand K, Pinto VZ, Colussi R, Zavareze ER, Dias ARG. Ozone oxidation of cassava starch in aqueous solution at different pH. Food Chemistry. 2014; 155:167-73. PMid: 24594170. https://doi.org/10.1016/j. foodchem.2014.01.058 